\title{
The influence of scopolamine on sucrose intake under absolute and relative test conditions
}

\author{
CHARLES F. FLAHERTY and ANNE B. MEINRATH \\ Rutgers University, New Brunswick, New Jersey 08903
}

\begin{abstract}
In three experiments, rats were injected with either saline or scopolamine hydrobromide in both simultaneous and successive contrast paradigms involving shifts between $32 \%$ and $4 \%$ sucrose solutions. One experiment included methyl scopolamine nitrate as a control for peripheral effects of the drug. Neither scopolamine hydrobromide nor methyl scopolamine nitrate had a clear-cut disinhibitory effect on the occurrence of negative contrast. Instead, scopolamine hydrobromide reduced intake of the sucrose solutions, particularly the $4 \%$ solution, both preshift and postshift.
\end{abstract}

Contrast effects occur in a variety of situations in which animals are exposed to multiple reward levels and are assessed by comparison of the instrumental or consummatory behavior of the shifted animals to animals receiving only one reward level (e.g., Crespi, 1942; Flaherty, Capobianco, \& Hamilton, 1973; Flaherty \& Largen, 1975). A negative contrast effect is defined as a decrement in performance for the smaller reward in animals shifted from the large to the small reward compared to animals exposed to only the small reward. A positive contrast effect is defined as an increment in performance for the large reward in animals shifted from a small to a large reward compared to animals exposed to only the large reward.

A frequent account of negative contrast assumes that the performance decrement in the shifted group is due to inhibition accruing from the reduction in reward level from the expected value (Black, 1968; Mackintosh, 1974). In support of this interpretation, Lombardi and Flaherty (1978) found that the introduction of a novel stimulus (a tone) following a reward shift from a $\mathbf{3 2 \%}$ sucrose solution to a $\mathbf{4 \%}$ sucrose solution produced an apparent disinhibitory effect in the consummatory responding. This effect involved an increment in lick rate of the shifted animals receiving the tone above the response level of a shifted group receiving no tone. Hence, negative contrast was reduced (but not eliminated) in the former group. Control conditions indicated that this effect was not the result of a rate-dependent effect or a nonspecific energization of behavior. Similarly, chlordiazepoxide has been found to eliminate successive negative contrast in consummatory behavior when the first drug injection is on the 2 nd or 3rd postshift day, an effect that can be interpreted

Research supported by a grant from the Rutgers Research Council to the first author. in terms of disinhibition (Flaherty, Lombardi, Wrightson, \& Deptula, in press; Vogel \& Principi, 1971).

Central cholinergic mechanisms have been implicated in processes that involve response inhibition (Carlton, 1969). Support for this proposition has been derived from demonstrations that centrally active anticholinergic drugs disinhibit responding in situations assumed to involve response inhibition, e.g., extinction (Hearst, 1959; Herblin, 1968; McKim, 1970), passive avoidance (Bohdanecky \& Jarvik, 1967; Carro-Ciampi \& Bignami, 1968; Meyers, 1965), habituation (Carlton, 1968), and punishment (Bignami, 1967), although recent studies have taken issue with this interpretation of the effects of scopolamine (e.g., Miczek \& Lau, 1975; Milar, Halgren, \& Heise, 1978).

The present experiments were an attempt to produce disinhibition in a negative contrast paradigm involving a shift from $32 \%$ to $4 \%$ sucrose solutions using the centrally active anticholinergic drug scopolamine hydrobromide. Two contrast paradigms were employed; a simultaneous contrast paradigm, in which all animals receive the two reward levels in an intermixed order with a short time interval between exposure to the different solutions (Flaherty \& Largen, 1975), and a successive negative contrast paradigm, in which one group of animals receives extensive exposure to the $32 \%$ sucrose and is then shifted once to the $4 \%$ solution while a control group is maintained on the $4 \%$ solution. Lombardi and Flaherty (1978) found the apparent disinhibitory effect of the tone in the successive paradigm, but not with the simultaneous paradigm. Thus, if the drug functions in the same manner as the tone, it is expected that negative contrast would be reduced by drug administration only in the successive paradigm. The effects of methyl scopolamine, the quarternary form of scopolamine, which does not cross the blood brain barrier when administered peripherally, were 
also assessed to ascertain that any effects were not due solely to the peripheral effects of the drug.

In Experiment 1 (simultaneous contrast), various doses of scopolamine hydrobromide were administered throughout the experiment. In Experiment 2 (successive contrast), scopolamine hydrobromide was administered during the last days of exposure to the $32 \%$ sucrose and during the entire postshift period. In Experiment 3 (successive contrast), both scopolamine hydrobromide and methyl scopolamine were administered on the 2nd, 3rd, and 4th days following the shift in sucrose solutions.

\section{EXPERIMENT 1}

\section{Method}

Subjects. The subjects were eight female albino rats (SpragueDawley), approximately 150 days old at the beginning of testing. The animals had had prior experience barpressing for food reward, but had had no exposure to sucrose solutions before the present experiment. The animals were housed individually under conditions of constant illumination.

Apparatus. Testing was conducted in a Plexiglas chamber measuring $30 \times 25 \times 25 \mathrm{~cm}$. On one side of the chamber, there were two $1.5-\mathrm{cm}$-diam holes spaced $21.7 \mathrm{~cm}$ apart and $4 \mathrm{~cm}$ above the wire-mesh floor. Two graduated drinking tubes, located outside the chamber, were programmed so that either tube could be automatically moved into a drinking position in which the orifice of the drinking spout was centered in the $1.5-\mathrm{cm}$-diam hole, flush with the outside wall of the chamber. Pilot lights, mounted on either side of the chamber close to the drinking access holes, were illuminated whenever the tube in closer proximity to that light was in the drinking position. A contact relay circuit was used to measure the licking response. All recording was done via standard relay equipment and a Data General Nova/ 2 computer in the adjacent room.

Procedure. The animals were randomly assigned to one of two groups $(\mathbf{N}=4)$. One group was maintained on ad-lib food and water for the duration of the experiment (mean body weight $=$ $250.5 \mathrm{~g}$ ). The second group was reduced to $85 \%$ (mean body weight $=175.5 \mathrm{~g}$ ) of their free-feeding weight and maintained at that level with limited food rations, given $30 \mathrm{~min}$ after the test session. Water was freely available in the home cage.

On the day prior to the 1st day, all animals were placed in the experimental chamber for a 5-min adaptation period. Following this procedure, the animals were given approximately $5 \mathrm{ml}$ of $32 \%$ sucrose solution in their home cages.

On each test day, the rats were placed in the apparatus with only the left tube in the drinking position. It remained available for a 1-min period starting from the time of the first lick. At the end of this period, the left tube was retracted and the right tube was moved into drinking position for a $1-\mathrm{min}$ period timed from the first lick. The right tube was then retracted and the left tube again became available. This alternation continued for a total of three presentations of each tube. If the animal did not begin licking within $5 \mathrm{~min}$, the timing of the 1 -min period began automatically.

The sucrose solutions in the tubes were varied systematically over a 4-day cycle. On 2 days, both tubes contained the same solution, $32 \%$ on one day, $4 \%$ on the other. On the remaining 2 days, one tube contained the $32 \%$ solution and the other contained the $4 \%$ solution. On one of these days, the $32 \%$ solution was in the right tube, and on the other day, it was in the left tube. Five cycles were presented, with a 3-day break between each cycle. Within each 4-day cycle, the actual sequence of the sucrose solutions was randomized, with the provision that, on the first day of Cycle 1, both tubes contained the $32 \%$ solution. During Cycles 2-5, the tubes were available for alternating 45-sec access periods.

The animals were tested for the one cycle with no drug administration. Beginning with Cycle 2, the animals were injected IP with either isotonic saline (SAL) or $.25, .50$, or $1.00 \mathrm{mg} / \mathrm{kg}$ of scopolamine hydrobromide (SCOPH) in a volume of $.1 \mathrm{cc} / 100 \mathrm{~g}$ of body weight (scopolamine from Sigma Chemical Corporation, St. Louis, Mo.). All animals received every drug dose, with the order of administration varied according to a Latin square plan and with the same sequence repeated twice (four animals/square). Each drug dose was administered for the complete 4-day cycle of contrast and control conditions. Injections were given $20 \mathrm{~min}$ prior to testing.

The sucrose solutions were prepared by weight (sugar/sugar + water) from commercial grade cane sugar and tap water. New solutions were prepared every 4 days and presented at room temperature.

\section{Results}

The rats licked more for $32 \%$ sucrose when $4 \%$ was the alternative than when $32 \%$ was the alternative $[F(1,6)=43.04, p<.01]$, a result apparent in the two leftmost bars of each panel in Figure 1. It can also be seen that this positive contrast effect was not substantially influenced by deprivation conditions or by drug injections [Concentration by Deprivation, $\mathrm{F}(1,6)=2.08, \mathrm{p}>.05$; Concentration by Drug, $F(3,18)<1.00$ ]. Deprivation did have an overall effect; the deprived animals licked more for the $32 \%$ solution than did the ad-lib animals $[F(1,6)=6.47$, $p<.05]$. However, there was no overall effect of scopolamine on lick rates for the $32 \%$ sucrose solution $[F(3,18)<1.00]$.

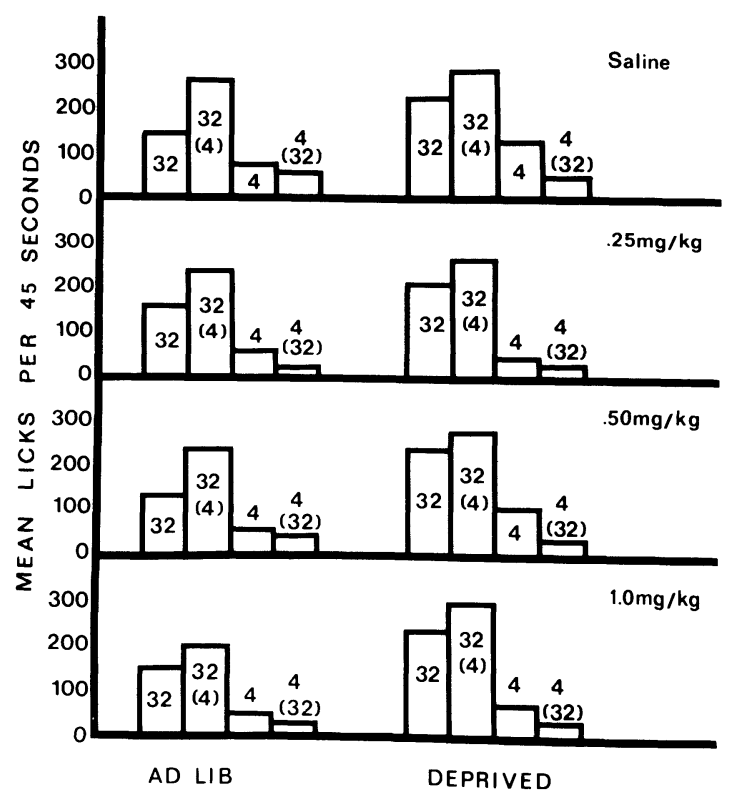

Figure 1. Mean licks per $45 \mathrm{sec}$ as a function of sucrose concentration, injection condition, and deprivation condition. The label “'32"' indicates lick rate for $32 \%$ sucrose. The label " $32(4)$ )" indicates the lick rate of $32 \%$ sucrose when the alternative tube contained $4 \%$ sucrose, etc. 
A negative contrast effect also occurred; the rats licked less for $4 \%$ sucrose when the alternative was $32 \%$ than when both tubes contained $4 \%[\mathrm{~F}(1,6)=$ $8.96, \mathrm{p}<.05]$. Negative contrast, like positive contrast, was uninfluenced by deprivation condition and drug condition [Deprivation by Concentration, $F(1,6)$ $=1.73, \mathrm{p}>.05$; Drug by Concentration, $\mathrm{F}(3,18)<$ 1.00]. Unlike the data obtained under the $32 \%$ conditions, deprivation did not have an overall effect on lick rate for the $4 \%$ solution $[F(1,16)=1.15$, $p>.05]$. Also unlike the data obtained with the $32 \%$ sucrose, the SCOPH did have an overall effect of suppressing lick rate for $4 \%$ sucrose $[F(3,18)=$ $6.24, p<.01]$. Subsequent analysis using Fisher's lsd $(\mathrm{p}=.05 ; \mathrm{Li}, 1964)$ indicated that the rats licked less $4 \%$ sucrose under all three drug conditions than under the saline condition.

\section{Discussion}

The results of this experiment indicate that "simultaneous" contrast, both positive and negative, obtained in the consumption of sucrose solutions is uninfluenced by SCOPH both in ad-lib and deprived rats. The results also demonstrate that SCOPH had an overall suppressive effect on the intake of the lower concentration sucrose solution, but did not reduce the intake of the $32 \%$ sucrose. Deprivation, on the other hand, increased the intake of the $32 \%$ solution, but did not reliably influence intake of $4 \%$ sucrose.

These overall effects of SCOPH seem consistent with previous studies which have shown that the drug reduces water intake and intake of dry food, but does not reduce the intake of wet mash or "liquid foods" (Block \& Fisher, 1975; Gentil, Stevenson, \& Mogenson, 1971; Miczek \& Lau, 1975). The effects of the drug on intake of the $4 \%$ sucrose solution are also consistent with reductions in the intake of an $8 \%$ dextrose solution resulting from .1 and $.5-\mathrm{mg} / \mathrm{kg}$ injections of SCOPH in squirrel monkeys (Miczek, 1973).

The failure of SCOPH to reduce the degree of negative contrast (i.e., decreased licking for $4 \%$ when compared with $32 \%$ sucrose) is consistent with previous results obtained with chlordiazepoxide, imipramine, and the presentation of a "disinhibitory" novel stimulus (Flaherty, Lombarde, Kapust, \& D'Amato, 1977; Lombardi \& Flaherty, 1978). However, the interpretation of this result is clouded by the overall tendency of SCOPH to reduce licking for the $4 \%$ solution under both contrast and noncontrast conditions.

In order to obtain more evidence concerning potential disinhibitory effects of SCOPH on consummatory contrast, a second experiment was conducted, one using a contrast design in which apparent disinhibition had been produced by a novel stimulus (Lombardi \& Flaherty, 1978).

\section{EXPERIMENT 2}

Animals given access to a $32 \%$ sucrose solution for $5 \mathrm{~min} /$ day for a number of days and then shifted to a $4 \%$ solution will drink substantially less than animals maintained on $4 \%$ sucrose all along (Flaherty et al., 1973). This result is termed a successive negative contrast effect, and this type of contrast has been shown to be susceptible to apparent disinhibition produced by the introduction of a novel stimulus (tone) coincident with the shift in sucrose concentration (Lombardi \& Flaherty, 1978). The purpose of this experiment was to examine the effects of SCOPH on this type of contrast. The general procedure was to give animals access to either $32 \%$ or $4 \%$ sucrose solutions for $5 \mathrm{~min} /$ day for 14 days and then shift the $32 \%$ animals to $4 \%$ for an additional 4 days. The animals initially trained on $4 \%$ were maintained on $4 \%$ over this period. During the last 4 preshift days and over all postshift days, half of the animals in each sucrose concentration group were injected with SCOPH $(1.0 \mathrm{mg} / \mathrm{kg})$ and the remaining animals were injected with SAL.

\section{Method}

Subjects. The subjects were 24 female albino rats (SpragueDawley), approximately 180 days old at the beginning of training. The animals had had prior experience barpressing for solid food reward, but no prior exposure to sucrose solutions. The animals were housed individually under conditions of constant illumination.

Apparatus. The apparatus consisted of two Plexiglas chambers, measuring $23 \times 23 \times 23 \mathrm{~cm}$ and housed in sound-attenuating boxes measuring $53 \times 37 \times 39 \mathrm{~cm}$. In the center of the rear wall of the chamber was a $1.5-\mathrm{cm}$-diam hole, $4 \mathrm{~cm}$ above the floor. Outside the chamber, a graduated cylinder was mounted so that the orifice of a metal drinking spout was centered in the $1.5-\mathrm{cm}$ hole, flush with the outside wall of the chamber.

In addition, two chambers identical to the one in Experiment 1 were used, although only one of the two available tubes was mounted in the drinking position. The pilot lights were not functioning during this experiment.

Contact relay circuits were used to measure the licking response. All recording was done via standard relay equipment and a Data General Nova/ 2 computer located in a adjacent room.

Procedure. All animals were deprived to $82 \%(\overline{\bar{X}}=224.22 \mathrm{~g})$ of their free-feeding body weights, and maintained at that level with a limited daily food ration. Water was always available in the home cage. The animals were fed their daily ration approximately $30 \mathrm{~min}$ after the test session.

The animals were randomly assigned to one of four groups (six animals per group). Two of the groups received $32 \%$ sucrose during training, the other two received $4 \%$ sucrose. On the day prior to the first training session, all animals were placed in the experimental chambers for a 5-min adaptation period. Following this procedure, the animals were given $5 \mathrm{ml}$ of either a $32 \%$ or a $4 \%$ sucrose solution in their home cages. Each rat received the solution it was to receive in the training phase.

Training was conducted in the following manner: Each animal was placed into the chamber with the tube containing the appropriate sucrose solution in place. Licks per minute were recorded for $5 \mathrm{~min}$, beginning with the animals' first lick. At the end of this period, the animals were removed and returned to their home cages. Training was continued in this manner for 14 days.

Beginning on Day 10 of the preshift period, the animals were injected IP (volume $=.1 \mathrm{cc} / 100 \mathrm{~g}$ of body weight) with either SAL 
or $1.0 \mathrm{mg} / \mathrm{kg}$ of $\mathrm{SCOPH} 20 \mathrm{~min}$ prior to testing. One group trained on $32 \%$ and one group trained on $4 \%$ sucrose received each dose level.

On Day 15 , the animals that had received the $32 \%$ solution were shifted to the $4 \%$ solution. The animals that received $4 \%$ sucrose in training continued to receive that solution. The SAL or SCOPH injections were continued for all 4 days of this postshift period, with all animals remaining in the same drug condition as in training.

The sucrose solutions were prepared as in Experiment 1 every 3 days.

\section{Results}

Over the first 10 preshift days, the rats given $32 \%$ sucrose licked at higher rates than the rats given $4 \%$ sucrose $[F(1,20)=17.46, p<.01]$. Over the last 4 preshift days (when the drug was administered), there was also an overall effect of sucrose concentration $[\mathrm{F}(1,20)=30.83, \mathrm{p}<.01]$. These results are apparent in Figure 2. Injection of the drug on Day 11 preshift led to a decline in lick rate for both the $32 \%$ and $4 \%$ sucrose groups $[F(1,20)=10.53, p<.01]$, but the decline was greater and longer lasting for the animals licking the $4 \%$ solution $[F(1,20)=5.17, p<.05]$. Comparison of the predrug lick rates with the lick rates on Day 14 indicated that, by Day 14, the rats in both sucrose groups had recovered to essentially their predrug lick rates [Day by Concentration by Drug, $F(1,20)$ $=1.32, \mathrm{p}>.05]$.

Shifting the $32 \%$ rats to $4 \%$ sucrose led to a decline in lick rate to below the level of the group maintained on $4 \%[F(1,20)=13.65, p<.01]$. In addition to this negative contrast effect, there was an overall effect of the drug; animals injected with SCOPH licked at lower rates than the saline animals

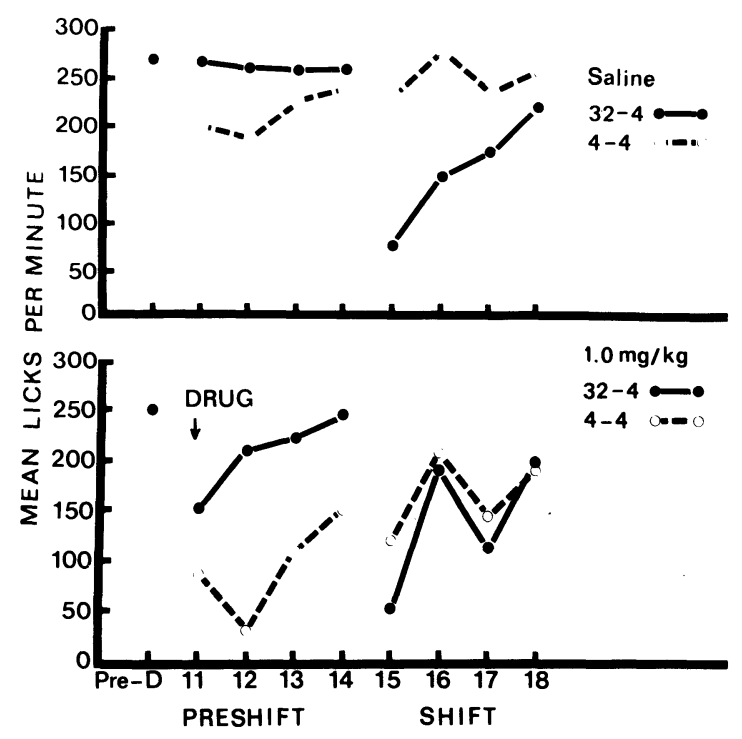

Figure 2. Mean licks per minute as a function of sucrose concentration, injection condition, and day of testing. Injections were begun on Day 11 and continued through Day 18.
$[F(1,20)=11.69, \mathrm{p}<.01]$. Examination of Figure 2 seems to suggest that SCOPH may have reduced the negative contrast effect. Analysis of the first postshift day indicated a large, but statistically unreliable, Drug by Concentration interaction $[F(1,20)=3.36$, $.05<\mathrm{p}<.10$, indicating that contrast was statistically equivalent in both SCOPH and SAL animals. But on the second postshift day, a reliable Drug by Concentration interaction $[F(1,20)=6.76, p<$ .05 ] indicated that contrast was significant in the SAL animals only. However, the conclusion that SCOPH disinhibited negative contrast is weakened by the fact that (1) the SAL and SCOPH shifted groups show a comparable drop in lick rate on Day 15, the first postshift day (a mean decrement of 181 licks/min in the SAL animals and a mean decrement of 193 licks/min in the SCOPH animals); (2) the level of the SCOPH control animals over the 4 postshift days is much lower than that of SAL controls (Concentration by Drug, $F(1,20)=4.46$, $\mathrm{p}<.05$, followed by lsd tests); (3) the shifted SCOPH animals did not show a reliably greater increment in lick rate from Day 15 to Day 16 than the SAL shift group $[F(1,10)=4.59, p>.05]$; and (4) both the shifted and control SCOPH groups dropped on Day 17.

\section{Discussion}

The results of this experiment show again that SCOPH produces a decrement in lick rate for sucrose solutions and that this decrement is greater for a lower concentration solution. The results also show that the drop in lick rate produced by a shift from $32 \%$ to $4 \%$ sucrose is not itself interfered with by SCOPH. There is some suggestion that contrast was reduced by SCOPH, particularly on Day 2, as the shifted and control SCOPH groups were not reliably different during the postshift period, but this seems to be due to the effects of SCOPH on the control animals rather than to an effect on the behavior of the shifted animals.

Thus, these data indicate that if inhibition is involved in the successive negative contrast effect produced by sucrose shifts, SCOPH does not appear to block this inhibition from occurring. In order to more fully investigate this effect, and in order to investigate the contribution of the peripheral effects of SCOPH, a third experiment was conducted.

\section{EXPERIMENT 3}

Previous studies have indicated that injections of chlordiazepoxide during both preshift and postshift, or on the first postshift day only, have no effect on contrast produced by the shift from $32 \%$ to $4 \%$ sucrose. However, injections of CDP on the second postshift day completely eliminates contrast (Vogel \& 
Principi, 1971; Flaherty et al., in press). One possible interpretation of this pattern of results in that inhibition is a more prominent causative agent of contrast on the second postshift day and that CDP has a disinhibitory effect when injected on this day. Inspection of the data from the Lombardi and Flaherty study indicated that the tone introduced during the postshift period had a somewhat greater effect on the 2nd postshift day than on the 1st day. The data from Experiment 2 also suggest that if there is an effect of SCOPH, it may be greater on Day 2 of postshift. Finally, it is possible that tolerance to SCOPH had occurred during the preshift administration in Experiment 2, perhaps obscuring any disinhibitory effects of the drug. Thus, one of the purposes of the present study was to see if an apparent disinhibitory effect of SCOPH would be produced if the drug injection was given for the first time on the 2nd postshift day.

A second purpose of the present experiment was to investigate whether the decremental effects that SCOPH has on licking for sucrose could be attributed to peripheral effects of the drug. Thus, separate groups of animals were injected with SAL, SCOPH, or methyl scopolamine nitrate (MSCOP). The latter compound is considered to have essentially peripheral effects (Goodman \& Gilman, 1975),

\section{Methods}

Subjects. The subjects were 30 male albino rats (SpragueDawley from Charles River), approximately 150 days old at the beginning of training. The animals had prior experience in a successive contrast experiment with a shift in sucrose solutions. They were housed individually under conditions of constant illumination.

Apparatus. The apparatus used was identical to that in Experiment 2.

Procedure. All animals were deprived to $80 \%(X=241.37 \mathrm{~g})$ of their free-feeding weights and maintained at that level with limited daily food rations. Water was always freely available in the home cages. The animals were fed their daily rations 30 min after each test session.

The animals were assigned to one of six groups (five animals per group). The animals' prior experience was balanced across groups. Three of these groups received $32 \%$ sucrose during training, the other three received $4 \%$ sucrose. On each training day, the animals were placed into the chamber with the tube containing the appropriate sucrose solution in place. Licks per minute were recorded for $5 \mathrm{~min}$, beginning with the animal's first lick. At the end of the 5-min period, the animals were removed and returned to their home cages. Training in this manner continued for 14 days.

Beginning with Day 15 , the groups that received the $32 \%$ solution in training were shifted to $4 \%$ for the duration of the experiment. The animals that received $4 \%$ sucrose in training continued to receive $4 \%$. On the 2 nd day of the postshift period, Day 16, all animals were injected IP (volume $=.1 \mathrm{cc} / 100 \mathrm{~g}$ of body weight) with SAL, $1.0 \mathrm{mg} / \mathrm{kg}$ SCOPH, or $.99 \mathrm{mg} / \mathrm{kg} \mathrm{MSCOP}$ (Sigma Chemical Corporation, St. Louis, Mo.) $20 \mathrm{~min}$ prior to testing. The two scopolamine solutions were equimolar. One group trained with $32 \%$ and one group trained with $4 \%$ sucrose received each drug condition, forming six groups. The injections were continued for the last 3 postshift days (Days 16-18).

Sucrose solutions were prepared as in Experiment 2.

\section{Results}

The terminal preshift lick rates and daily postshift lick rates for each group are presented in Figure 3. Mean lick rate on the last 3 preshift days indicated that the animals given $32 \%$ sucrose licked at higher rates than the animals given $4 \%$ sucrose $[\mathrm{F}(1,24)=$ $11.16, \mathrm{p}<.01]$; there was no effect of the drug condition (a pseudovariable at this point) on lick rates $[F(2,24)=1.44, p>.05]$.

The shift of the $32 \%$ groups to $4 \%$ produced a substantial drop in lick rate to levels below those of the unshifted controls $[\mathrm{F}(1,24)=66.34, \mathrm{p}<.001]$. This negative contrast effect, apparent on the 1 st day postshift, was uninfluenced by the nominal drug condition, drug still a pseudovariable on this day $[\mathrm{F}(2,24)<1.00]$.

On Postshift Days 2-4, the SCOPH-injected groups licked at a reliably lower rate than the SAL animals

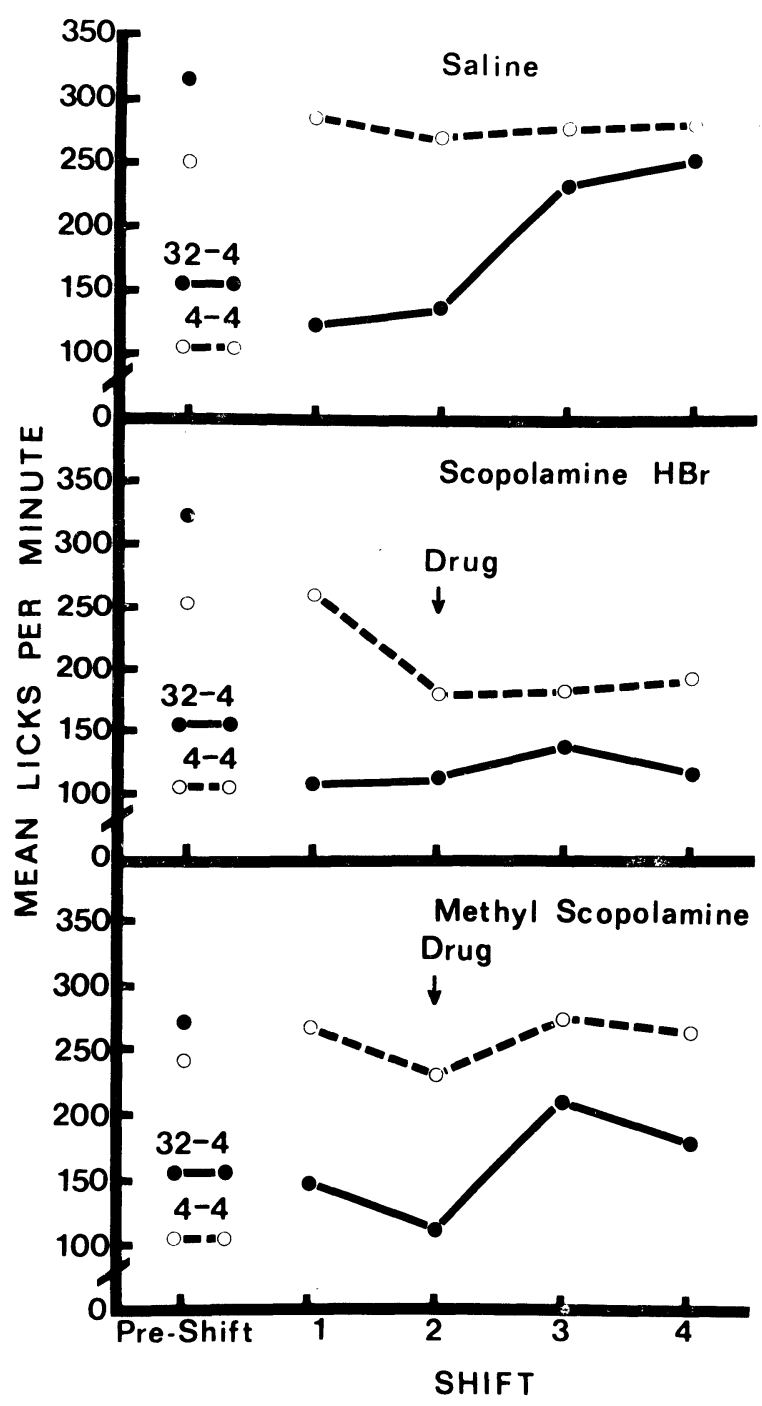

Figure 3. Mean licks per minute as a function of sucrose concentration, injection condition, and day of testing. Injections were given on Shift Days 2-4. 
$[F(2,24)=9.27, p<.01$; followed by lsd tests, $\mathrm{p}=.05]$. The MSCOP animals licked at an intermediate rate, not reliably different from the SAL groups, but reliably greater than the SCOPH groups. During these last 3 postshift days, an overall contrast effect was maintained $[F(1,24)=17.87, p<.01]$ and there was no indication that the injection of either scopolamine compound reduced the size of the contrast effect $[\mathrm{F}(2,24)<1.00]$.

A reliable Concentration by Day interaction $[F(2,48)=4.04, p<.05]$ indicated that the shifted animals tended to recover from contrast over the postshift period. With regard to degree of recovery from contrast, examination of Figure 3 indicates that the MSCOP animals appear to behave in a manner more similar to the saline animals than do the SCOPH animals-who show no trend toward recovery. However, there was no statistical support for a differential effect of the drug on recovery [Drug by Concentration interaction, $F(2,24)<1.00$ ].

\section{Discussion}

The results of this experiment indicate that neither SCOPH nor MSCOP reduce negative contrast in the successive paradigm. Again, as in Experiments 1 and 2 , SCOPH produced a decrement in responding for the $4 \%$ sucrose solution. MSCOP produced a slight decrement in lick rate (although not statistically reliable), and the MSCOP animals behaved in a manner similar to that of the SAL-injected animals. Thus the effects of SCOPH on consumption of sucrose solutions appear to be attributable to the central effects of the drug.

\section{GENERAL DISCUSSION}

The results of the three experiments demonstrate the following:

(1) Scopolamine hydrobromide does not effect the size of the negative or positive contrast effect in a simultaneous contrast paradigm involving a shift between $32 \%$ and $4 \%$ sucrose solutions.

(2) Neither scopolamine hydrobromide nor methyl scopolamine have a clear-cut effect on negative contrast in a successive negative contrast paradigm involving a shift from $32 \%$ to $4 \%$ sucrose. Although there was a suggestion that scopolamine hydrobromide might reduce contrast, particularly on Day 2 of the postshift period in Experiment 2, this was primarily a result of the effect of scopolamine on lick rate for $4 \%$ and not an effect on the decrement in the shifted animals. There was definitely not an effect of the same drug in Experiment 3. In fact, in the latter study, the animals given scopolamine hydrobromide showed no evidence of recovery over the postshift period. This result is in agreement with the finding that septal lesions, which have been suggested to produce a deficit in response inhibition (Dickinson, 1972; Donovick, 1968; Hamilton, 1970; McCleary, 1961), have no effect on the size of the negative contrast effect when rats are shifted from $32 \%$ to $4 \%$ sucrose in an open field (Flaherty, Powell, \& Hamilton, 1979). It is still possible, however, that any disinhibitory effects of scopolamine may be obscured by its effects on the consumption of sucrose solutions.

(3) Finally, scopolamine hydrobromide tends to reduce lick rate for sucrose solutions, with a more pronounced effect on the consumption of $4 \%$ sucrose. This reduction seems to be due more to the central effects of the drug, as methyl scopolamine (with primarily peripheral effects) results in little lick-rate decrement. This suggests that sucrose solutions should be used with caution when the intent of the study is to investigate the disinhibitory effects of scopolamine.

\section{REFERENCES}

Bignami, G. Anticholinergic agents as tools in the investigation of behavioral phenomena. In H. Brill (Ed.), Neuro-psychopharmacology. Amsterdam: Excerpta Medica International Congress Series No. 129, 1967.

BLACK, R. W. Shifts in magnitude of reward and contrast effect in instrumental and selective learning: A reinterpretation. Psychological Review, 1968, 75, 114-126.

Block, M. L., \& Fisher, A. E. Cholinergic and dopaminergic blocking agents modulate water intake elicited by deprivation, hypovolemia, hypertonicity and isoproterenol. Pharmacology, Biochemistry, and Behavior, 1975, 3, 251-262.

Bohdanecky, Z., \& Jarvik, M. E. Impairment of one-trial passive avoidance learning in mice by scopolamine, scopolamine methyl-bromide and physostigmine. International Journal of Neuropharmacology, 1967, 6, 217-222.

Carlton, P. L. Brain acetylcholine and habituation. In P. B. Bradley \& M. Fink (Eds.), Progress in brain research. New York: Elsevier, 1968.

Carlton, P. L. Brain acetylcholine and inhibition. In J. T. Tapp (Ed.), Reinforcement and behavior. New York: Academic Press, 1969.

Carro-Ciampi, G., \& Bignami, G. Effects of scopolamine on shuttle-box avoidance and go-no-go discrimination: Responsestimulus relationships, pretreatment baselines and repeated exposure to drug. Psychopharmacologia, 1968, 13, 89-105.

Crespi, L. P. Quantitative variation in incentive and performance in the white rat. American Journal of Psychology, 1942, 55, 467-517.

Dickinson, A. Septal damage and response output under frustrative nonreward. In R. A. Boakes \& M. S. Halliday (Eds.), Inhibition and learning. London: Academic Press, 1972.

Donovick, P. J. Effects of localized septal lesions on hippocampal EEG activity and behavior in rats. Journal of Comparative and Physiological Psychology, 1968, 66, 569-578.

Flaherty, C. F., Capobianco, S., \& Hamilton, L. W. Effects of septal lesions on retention of negative contrast. Physiology \& Behavior, 1973, 11, 625-631.

Flaherty, C. F., \& Largen, J. Within-subjects positive and negative contrast effects in rats. Journal of Comparative and Physiological Psychology, 1975, 88, 653-664.

Flaherty, C. F., Lombardi, B. R., Kapust, J., \& D'Amato, M. R. Incentive contrast undiminished by extended testing, 
imipramine, or chlordiazepoxide. Pharmacology, Biochemistry, and Behavior, 1977, 7, 315-322.

Flaherty, C. F., Lombardi, B. R., Wrightson, J., \& De ptula, D. Conditions under which chlordiazepoxide influences successive gustatory contrast. Psychopharmacology, in press.

Fi.aherty, C. F., Powell, G., \& Hamilton, L. W. Septal lesions, sex, and incentive shift effects on open field behavior of rats. Physiology \& Behavior, 1979, 22, 903-909.

Gentil, C. G., Stevenson, J. A. F., \& Mogenson, G. J. Effect of scopolamine on drinking elicited by hypothalmic stimulation. Physiology \& Behavior, 1971, 7, 639-641.

Goodman, L. S., \& Gilman, A. (EDs.), The pharmacological basis of therapeutics (5th ed.) New York: Macmillan, 1975.

Hamilton, L. W. Behavioral effects of unilateral and bilateral septal lesions in rats. Physiology \& Behavior, 1970, 5, 855-859.

HEARST, E. Effects of scopolamine on discriminated responding in the rat. Journal of Pharmacology and Experimental Therapeutics, 1959, 125, 349-358.

Herblin, W. F. Extinction reversal by scopolamine. Psychonomic Science, 1968, 13, 43-44.

LI, J. C. R. Statistical inference I. Ann Arbor: Edwards Brothers, 1964.

Lombardi, B. R., \& Flaherty, C. F. Apparent disinhibition of successive but not of simultaneous negative contrast. Animal Learning \& Behavior, 1978, 6, 30-42.
Mackintosh, N. J. The psychology of animal learning. London: Academic Press, 1974.

MCCleary, R. A. Response specificity in the behavioral effects of limbic system lesions in the cat. Journal of Comparative and Physiological Psychology, 1961, 54, 605-613.

McKIM, W. A. The effects of scopolamine on the extinction of a continuously reinforced response. Psychonomic Science, 1970, 20, 281-282.

MeYERS, B. Some effects of scopolamine on a passive avoidance response in rats. Psychopharmacologia, 1965, 8, 111-119.

MiczeK, K. A. Effects of scopolamine, amphetamine and chlordiazepoxide on punishment. Psychopharmacologia, 1973, 28, 373-389.

Micze K, K. A., \& LAU, P. Effects of scopolamine, physostigmine and chlordiazepoxide on punished and extinguished water consumption in rats. Psychopharmacologia, 1975, 42, 262-269.

Milar, K. S., Halgren, C. R., \& Heise, G. A. A reappraisal of scopolamine effects on inhibition. Pharmacology, Biochemistry, and Behavior, 1978, 9, 307-313.

Vogel, J. R., \& Principi, K. Effects of chlordiazepoxide on depressed performance after reward reduction. Psychopharmacologia, 1971, 21, 8-12.

(Received for publication June 11, 1979; revision accepted August 20,1979.) 